\title{
A semi-analytical model for the propagation of Rossby waves in slowly varying flow
}

\author{
LIU Fei ${ }^{1,2}$, CHAO JiPing ${ }^{3}$, HUANG Gang ${ }^{1,4^{*}} \&$ FENG LiCheng ${ }^{3}$ \\ ${ }^{1}$ Key Laboratory of Regional Climate-Environment Research for Temperate East Asia, Institute of Atmospheric Physics, Chinese Academy of \\ Sciences, Beijing 100029, China; \\ ${ }^{2}$ International Pacific Research Center, University of Hawaii at Manoa, Honolulu 96822, USA; \\ ${ }^{3}$ National Marine Environmental Forecasting Center, Beijing 100081, China; \\ ${ }^{4}$ State Key Laboratory of Numerical Modeling for Atmospheric Sciences and Geophysical Fluid Dynamics, Institute of Atmospheric Physics, \\ Chinese Academy of Sciences, Beijing 100083, China
}

Received May 17, 2011; accepted June 13, 2011

\begin{abstract}
Instead of using complicated general circulation models (GCMs), a simple semi-analytical model based on ray theory has been used to study energy evolution and ray path of Rossby waves in slowly varying mean flows. Our model yields similar results to those calculated from barotropic models, and also provides a chance to study Rossby waves in the slowly varying flows with both vertical and meridional shears. The model results show that upward Rossby waves can only grow in westerlies, and decay when further ascend. The baroclinic Rossky waves are restrained by the $\beta$ effect in lower latitude. In the westerly jet with meridional and vertical shears, the barotropic Rossby waves originated from south of the westerly jet, and these can grow while propagating upper-northward. The baroclinic Rossby waves originated from north of the westerly jet and can grow while propagating upward and southward. Such a semi-analytical model provides a simple forecasting tool to allow study of the local weather anomalies to the heating/topography forcing associated with the global warming.
\end{abstract}

Rossby waves, ray theory, energy evolution, semi-analytical, slowly varying flow

Citation: $\quad$ Liu F, Chao J P, Huang G, et al. A semi-analytical model for the propagation of Rossby waves in slowly varying flow. Chinese Sci Bull, 2011, 56: 2727-2731, doi: 10.1007/s11434-011-4626-5

Global teleconnection provides an important way to improve prediction on different temporal and spatial scales. Usually the teleconnection can be separated into the extratropical responses of the ENSO mode [1-10], the extratropical responses of monsoon mode [11-19], and the downstream responses to the upstream wave sources [17-20]. The Chinese winter ice storms in 2008 and the worst South China drought in 2010 may also result from local teleconnection responses to the tropical or high latitude anomalies.

In fact, it is usually Rossby waves that transport energy in global teleconnection [7,20,21]. In sub-equatorial regions, Rossby waves can propagate in the westerly jet $[13,20,22]$. Such Rossby wave sources may come from tropical heating coupled with mean vertical shear [23], or higher-latitude

\footnotetext{
*Corresponding author (email: hg@mail.iap.ac.cn)
}

topography [24].

To understand global teleconnection, it is necessary to study the growth and ray path of Rossby waves under mean flow conditions. This allows prediction of the local weather or climate based on the pre-existent mean flows and wave sources. Earlier theories of Rossby waves identified the theoretical instability criteria [21, 25-29]: (a) consistent with the results of Hoskins and Karoly [7], "great circle" propagation was simulated in a uniform westerly; (b) the "guided" Rossby waves $(l / k>0)$ develop on the south of the westerly jet, where $\partial U / \partial y>0$, and the "trailing" Rossby waves $(l / k>0)$ develop on the north side of the westerly jet, where $\partial U / \partial y<$ 0 [21]; (c) in positive $(\partial U / \partial y>0)$ sheared mean flow, northward Rossby waves turn back at a turning point, while the southward Rossby waves approach the critical level directly [30,31]; (d) the divergent effect is necessary for the prop- 
agation of Rossby waves [32]; and (e) in a strong westerly jet, the Rossby waves oscillate and propagate downstream [20,33-35].

Although previous works identified the instability criteria, these works are usually limited to the barotropic or baroclinic modes separately, and are hardly used for realistic prediction [27-31,36]. It is difficult to find an analytical solution of Rossby waves under realistic mean flows that have both meridional and vertical shears. In this situation, general circulation models (GCMs) or two-layer models have to be used $[37,38]$.

To study the evolution of Rossby waves in realistic mean flows, a simple semi-analytical model based on ray theory has been developed [39]. Under the WKBJ approximation, the free wave solutions can be obtained from the potential vorticity equation, and the Rossby waves propagate along a ray with energy transported by the group velocity. For initial Rossby waves, this simple model not only proves the works of Huang [20] and Chen and Chao [21], but also provides the ray path and energy evolution of Rossby waves under realistic mean flows without complicated calculation of GCMs.

\section{Formulation}

On the $\beta$-plane, the quasi-geostrophic potential vorticity equation becomes [29]

$$
\frac{\partial q}{\partial t}+\frac{\partial \psi}{\partial x}\left(\frac{\partial q}{\partial y}+\beta\right)-\frac{\partial \psi}{\partial y} \frac{\partial q}{\partial x}=0
$$

where $q=\nabla_{h}^{2} \psi+\frac{f_{0}^{2}}{\rho_{0}} \frac{\partial}{\partial z}\left(\frac{\rho_{0}}{N^{2}} \frac{\partial \psi}{\partial z}\right)$ is the quasi-geostrophic potential vorticity, $\rho_{0}$ is the mean atmospheric density, $\psi=P / f_{0} \rho_{0}, \quad \beta=\frac{\partial f}{\partial y}, \quad N=\left(\frac{g}{\theta_{0}} \frac{\partial \theta_{0}}{\partial z}\right)^{1 / 2} \quad$ is the BrantVäisälä frequency, $P$ is the pressure disturbance. Introduce the values of $L, \Omega, H_{0}$, which have their usual values, where $\tilde{t}=\Omega t, \quad(\tilde{x}, \tilde{y})=(x, y) / L, \quad \tilde{z}=z / H_{0}, \quad \tilde{U}=U / L \Omega, \quad \tilde{\psi}=$ $\psi / \psi^{*}$, and $\psi^{*}=\Omega L^{2}$. Following the small-disturbance method, the linear disturbance equation can be obtained as [29]

$$
\left(\frac{\partial}{\partial t}+U \frac{\partial}{\partial x}\right)\left\{\nabla_{h}^{2} \psi+\frac{1}{\rho_{0}} \frac{\partial}{\partial z}\left(\rho_{0} \alpha^{2} \frac{\partial \psi}{\partial z}\right)\right\}+\beta_{A} \frac{\partial \psi}{\partial x}=0,
$$

where ' $\sim$ ' is neglected for simplicity, $\alpha^{2}=\left(L / L_{c}\right)^{2}$, and $L_{c}=N H_{0} / f_{0}$ is the Rossby radius of deformation. The general potential vorticity gradient is defined as

$$
\beta_{A}=2 \cos \phi-\frac{\partial^{2} U}{\partial y^{2}}-\frac{1}{\rho_{0}} \frac{\partial}{\partial z}\left(\rho_{0} \alpha^{2} \frac{\partial U}{\partial z}\right)
$$

If $\psi=\Psi(x, y, z, t) \mathrm{e}^{-r z}$, and $r=\frac{1}{2} \frac{\partial}{\partial z} \ln \left(\rho_{0} \alpha^{2}\right)$ is a constant, (2) becomes

$$
\left(\frac{\partial}{\partial t}+U \frac{\partial}{\partial x}\right)\left\{\nabla_{h}^{2} \Psi+\alpha^{2} \frac{\partial^{2} \Psi}{\partial z^{2}}-G \Psi\right\}+\beta_{A} \frac{\partial \Psi}{\partial x}=0,
$$

where $G=\alpha^{2} r^{2}$. By the WKBJ approximation, the solution of a nearly-plane wave takes the form of

$$
\Psi=A(T, X, Y, Z) \mathrm{e}^{i \varphi},
$$

where the phase $\varphi=k x+l y+n z-\sigma t, k, l, n$ are the zonal, meridional and vertical wavenumber, respectively. $\sigma$ is the frequency. This model has the scale relation of

$$
T=\varepsilon t, X=\varepsilon x, Y=\varepsilon y, Z=\varepsilon z,
$$

where $\varepsilon$ is a small number and $\varepsilon<<1$. Substituting (5) and (6) into (4) we obtain the zero-order dispersion equation:

$$
\sigma=U k-\frac{\beta_{A} k}{K^{2}+G}
$$

where $K^{2}=k^{2}+l^{2}+n^{2}$.

Without considering the temporal variation of mean flows, the ray theory gives [39]

$$
\begin{gathered}
\frac{D_{g} X}{D T}=C_{g X}=\frac{\partial \sigma}{\partial k}=U-\frac{\beta_{A}}{\left(K^{2}+G\right)}+\frac{2 \beta_{A} k^{2}}{\left(K^{2}+G\right)^{2}}, \\
\frac{D_{g} Y}{D T}=C_{g Y}=\frac{\partial \sigma}{\partial l}=+\frac{2 \beta_{A} k l}{\left(K^{2}+G\right)^{2}}, \\
\frac{D_{g} Z}{D T}=C_{g Z}=\frac{\partial \sigma}{\partial n}=+\frac{2 \alpha^{2} \beta_{A} k n}{\left(K^{2}+G\right)^{2}}, \\
\frac{D_{g} k}{D T}=-\frac{\partial \sigma}{\partial X}, \\
\frac{D_{g} l}{D T}=-\frac{\partial \sigma}{\partial Y}, \\
\frac{D_{g} n}{D T}=-\frac{\partial \sigma}{\partial Z},
\end{gathered}
$$

where $\frac{D_{g}}{D T}=\frac{\partial}{\partial T}+C_{g X} \frac{\partial}{\partial x}+C_{g Y} \frac{\partial}{\partial y}+C_{g Z} \frac{\partial}{\partial z}$ is the variation in the Lagrange coordinate. (7) and (8) describe the path of Rossby waves by integrating from any initial locations $\left(X_{0}, Y_{0}, X_{0}\right)$ and wave characteristics $\left(k_{0}, l_{0}, n_{0}, \sigma_{0}\right)$. The kinetic energy, $E=\left(K^{2}+\alpha^{2} r^{2}\right) A_{0}^{2}$, along a ray can be determined by [21]

$$
\begin{aligned}
\frac{D_{g} E}{D T}= & A_{0}^{2}\left\{2 k l \frac{\partial U}{\partial Y}+2 k n \alpha^{2} \frac{\partial U}{\partial Z}+\frac{2 k n \beta_{A}}{\left(K^{2}+G\right)} \frac{\partial \alpha^{2}}{\partial Z}\right\} \\
& -E \nabla_{3} \cdot \vec{C}_{g} .
\end{aligned}
$$


So this semi-analytical model, (7) and (9), forms a selfcontained system, which can be calculated by the RungeKutta method for any initial disturbances. In the following experiments, we selected $k_{0}=1$.

\section{Rossby waves in baroclinic mean flows}

Using this semi-analytical model, Rossby waves can be studied under baroclinic $\left(U_{Z} \neq 0\right)$ mean flows. The potential vorticity gradient, $\beta_{A}=2 \cos (\phi)-2 \alpha^{2} r U_{Z}-\alpha^{2} U_{Z Z}$, is determined not only by $\beta$, but also by the vertical variation of mean flows. In this work, $\phi_{0}=35^{\circ}$ is used.

Scenarios with positive $\left(U_{Z}>0\right)$ and negative $\left(U_{Z}<0\right)$ vertical shears have been studied. The basic flows are given as

$$
\begin{array}{ll}
U=U_{Z} Z & U_{Z}>0, \\
U=5 U_{Z}-U_{Z} Z & U_{Z}<0,
\end{array}
$$

and all upward Rossby waves are initiated at $Z=0.2$.

For positive vertical shears, Figure 1(+) shows that upward Rossby waves are unstable, they ascend slowly and grow, but then decay as they rise higher. Under conditions of strong vertical shear, Rossby waves propagate upward rapidly and have a short life cycle. Under conditions of negative vertical shear, Figure 1(-) shows that the Rossby waves propagate upward but decay rapidly, and this becomes more obvious under strong negative vertical shear. This is consistent with the results obtained from the twolayer model, which shows that vertical easterly shear will trap the energy in the lower troposphere [23]. In the summer, the tropical easterly occurs in the upper troposphere and restricts the upward propagation of Rossby waves [36]. The Rossby waves can propagate upward and grow in the weak westerly, but decay in the strong westerly.

The downward $(n<0)$ Rossby waves are initiated at $Z=1$. Under conditions of positive vertical shear, Figure 2 shows that the Rossby waves propagate downward and grow first,
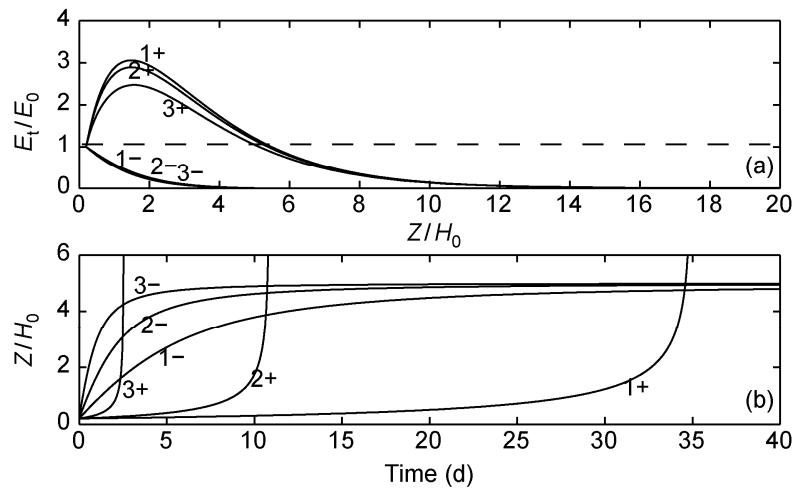

Figure 1 Energy evolution (a) and ray path (b) of upward Rossby waves. The vertical shears $U_{Z}$ are $\pm 5 \mathrm{~m} \mathrm{~s}^{-1} \mathrm{H}_{0}^{-1}, \pm 10 \mathrm{~m} \mathrm{~s}^{-1} \mathrm{H}_{0}^{-1}$, and $\pm 20 \mathrm{~m} \mathrm{~s}^{-1} \mathrm{H}_{0}^{-1}$, marked by $1 \pm, 2 \pm, 3 \pm$, respectively. Here $k_{0}=1$.
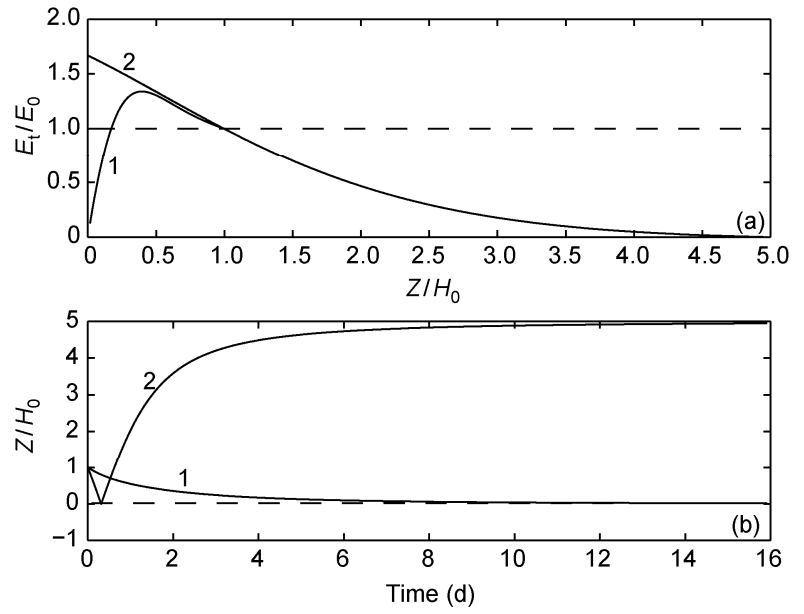

Figure 2 Energy evolution (a) and ray path (b) of downward Rossby waves. The vertical shears $U_{Z}$ are $20 \mathrm{~m} \mathrm{~s}^{-1} \mathrm{H}_{0}^{-1}$ and $-20 \mathrm{~m} \mathrm{~s}^{-1} \mathrm{H}_{0}^{-1}$, marked by 1 and 2 , respectively. Here $k_{0}=1$.

but then decay rapidly as they sink lower. Under conditions of negative vertical shear, Figure 2 shows that the Rossby waves can grow and propagate downward. Here we assume that the boundary layer acts as a mirror to reflect the wave energy upward without damping, and $n=-n$ when $Z<0$. After reflection, the Rossby waves ascend and decay in the upper troposphere.

The $\beta$ effect can be studied using this model. Under conditions of positive vertical shear $U_{Z}=5 \mathrm{~m} \mathrm{~s}^{-1} \mathrm{H}_{0}^{-1}$, four upward Rossby wave sources are located at $5^{\circ} \mathrm{N}, 25^{\circ} \mathrm{N}, 35^{\circ} \mathrm{N}$, and $45^{\circ} \mathrm{N}$, respectively. As shown in Figure 3, it is difficult for Rossby waves to develop near the tropics, where $\beta$ is large (line 1 of Figure 3). On the other hand, Rossby waves can propagate upward and grow rapidly in higher latitudes because of the small $\beta$ effect (line 4 of Figure 3 ). Hence the $\beta$ effect restrains the growth of Rossby waves.
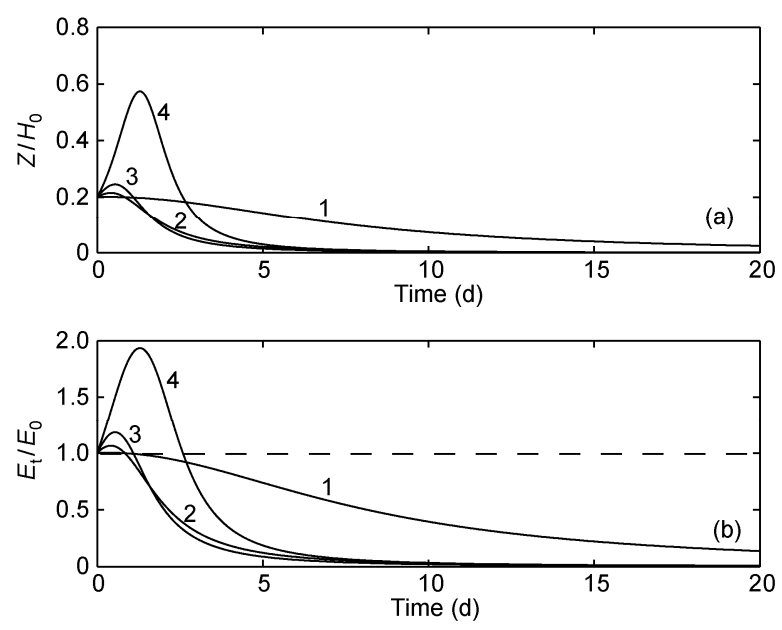

Figure 3 Ray path (a) and energy evolution (b) of upward Rossby waves, which are initiated at $5^{\circ} \mathrm{N}, 25^{\circ} \mathrm{N}, 35^{\circ} \mathrm{N}, 45^{\circ} \mathrm{N}$, and marked by $1,2,3$, and 4 , respectively. Here $n_{0}=1$. 


\section{Rossby waves in the westerly jet with both the meridional and vertical shears}

Using this model, we can study Rossby waves under realistic westerly jet conditions with both meridional and vertical shears. We assume a jet of semi-columniform form, which can be described as

$$
U=U_{0}\left\{\frac{1-\cos \left(\phi \pi / \phi_{0}\right)}{2}\right\}\left\{\cos \left(z / z_{0}-1\right) \pi\right\},
$$

where $\phi_{0}=35^{\circ}, z_{0}=1, U_{0}=15 \mathrm{~m} \mathrm{~s}^{-1}$. To obtain the frequency equation of Rossby waves, the WKBJ approximation was used, which means that the mean flows must vary more slowly than the Rossby waves on a spatial scale. We have adopted a small magnitude of $15 \mathrm{~m} \mathrm{~s}^{-1}$ for the westerly jet to satisfy the criteria of WKBJ (eq. 5.22 of [7]).

To describe the evolution of Rossby waves originated from every point in the $y-z$ field, we define the instability of Rossby waves as

$$
\begin{array}{r}
I_{R}=\left\{\text { Days of } t \mid E_{t}>E_{0}\right\}, \text { when } E_{1 / 4 \mathrm{day}}>E_{0}, \\
I_{R}=\left\{-\frac{1}{\text { Days of } t} \mid E_{t}=0.8 E_{0}\right\}, \text { when } E_{1 / 4 \mathrm{day}}<E_{0} .
\end{array}
$$

When the energy on the $1 / 4$ day $\left(E_{1 / 4}\right)$ is larger than the original energy $\left(E_{0}\right)$, we assume that the Rossby waves will develop, and when the energy on the $1 / 4$ day is less than the original energy, we assume that the Rossby waves will decay.
For initial northward Rossby waves $(l>0)$, the unstable field occurs to the south of the westerly jet (Figure 4(a), (b)), especially the lower and southerly part of westerly jet. Even for more barotropic Rossby waves with $n=0.2$ (Figure 4(e), (f)), the south part of the jet becomes more unstable. This means that the Rossby waves with a more barotropic component can propagate upper-northward and grow in the westerly jet when initiated from the south of the westerly jet.

For initial southward Rossby waves $(l<0)$, the unstable field occurs to the lower and northerly part of the westerly jet (Figure 4(c), (d), (g), (h)), and Rossby waves can propagate upward and southward and grow in the westerly jet. The more baroclinic Rossby waves with $n=1$ (Figure 4(c), (d)) can develop more strongly than the barotropic Rossby waves with $n=0.2$ (Figure $4(\mathrm{~g})$, (h)), because the baroclinic Rossby waves can absorb more available potential energy from the baroclinic mean flow.

\section{Summary and discussion}

In this paper, a simple semi-analytical model based on ray theory [39] has been used to study Rossby waves under mean flow conditions. Unlike the analytical solutions of previous theories, this semi-analytical model can predict the path and energy evolution of Rossby waves under realistic mean flows that have both barotropic (meridional) and baroclinic (vertical) shears.

When omitting the vertical variables, this model becomes a barotropic model and produces similar results to those
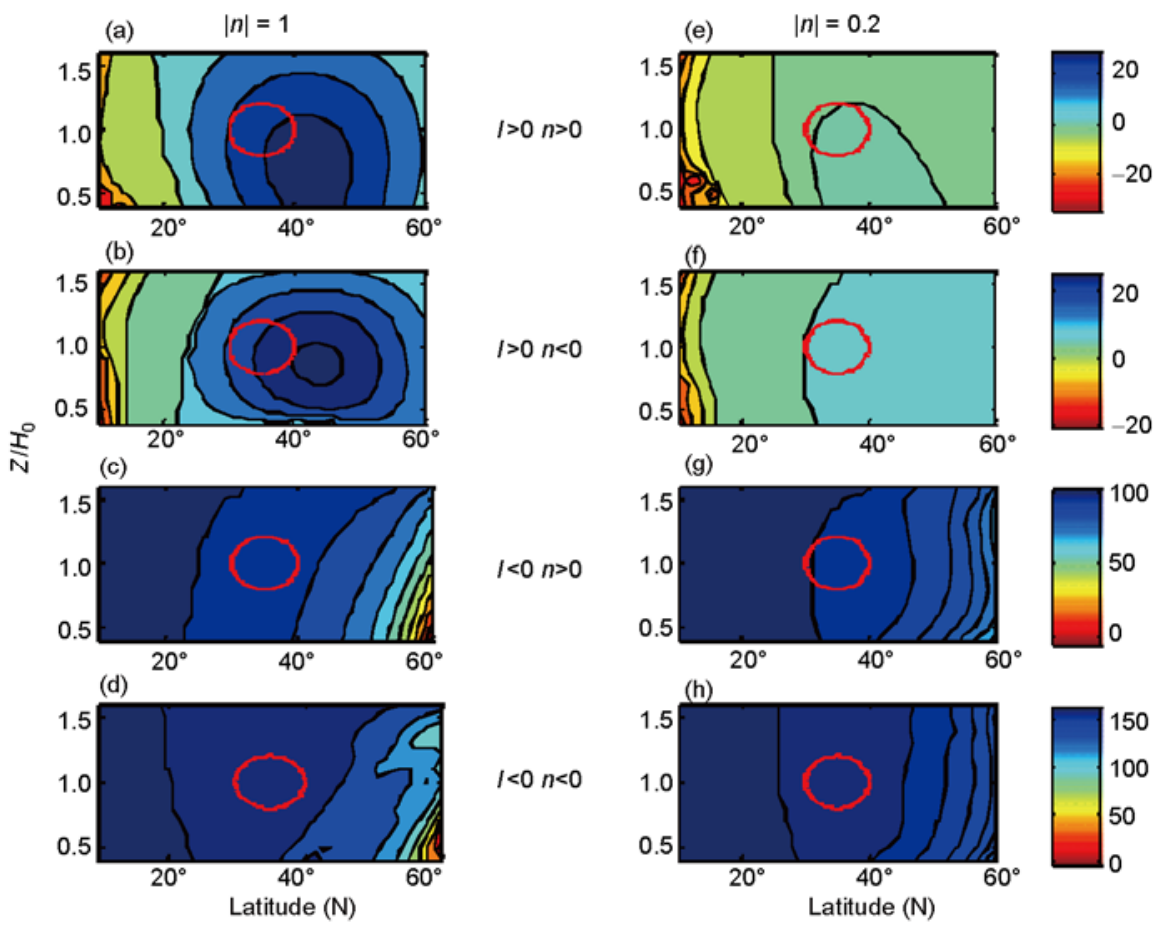

Figure 4 Rossby instability $\left(I_{\mathrm{R}}\right)$ in the westerly jet that has vertical and meridional shears. The red circle represents the westerly center, where $U=0.9 U_{0}$. The red/blue shade represents the unstable/stable field of Rossby waves. 
from other the previous work. Under conditions of mean flows with vertical shear, our model shows that Rossby waves propagate upwards in weak westerlies [36]. Baroclinic Rossby waves become more unstable at the high latitudes, because the $\beta$ effect restrains the growth of Rossby waves (Figure 3).

Under mean flow regimes that have both meridional and vertical shears, the barotropic Rossby waves grow when propagating upward and northward from the south part of westerly jet (Figure 4(e)). The baroclinic Rossby waves also grow when propagating upwards and southward from the north part of the westerly jet (Figure 4(c)).

Such a semi-analytical model provides a very simple prediction tool to study Rossby waves, which are important for the global teleconnection. In this work we have only studied idealized mean flows, and observed mean flows should be included in the future work. With this simple model, we can study the mid- and high-latitude teleconnection associated with Chinese climate $[17,18,20,40]$.

The authors are grateful to the two anonymous reviewers for their insightful comments that led to a significant improvement of the manuscript. This work was supported by the National Natural Science Foundation of China (U0733002, 40810059005, 40890155, 40906014 and 40976015) and the Youth Marine Science Foundation of State Oceanic Administration (2010218).

1 Bjerknes J. A possible response of the atmospheric Hadley circulation to equatorial anomalies of ocean temperature. Tellus, 1966, 18: $820-829$

2 Bjerknes J. Atmospheric teleconnections from the equatorial Pacific. Mon Weather Rev, 1969, 97: 163-172

3 Namias J. Thermal communication between the sea surface and the lower troposphere. J Phys Oceanogr, 1973, 3: 373-378

4 Namias J. Negative ocean-air feedback systems over the North Pacific in the transition from warm to cold seasons. Mon Weather Rev, 1976, 104: 1107-1121

5 Horel J D, Wallace J M. Planetary-scale atmospheric phenomena associated with the Southern Oscillation. Mon Weather Rev, 1981, 109: 813-829

6 Wallace J M, Gutzler D S. Teleconnections in the geopotential height field during the Northern Hemisphere winter. Mon Weather Rev, 1981, 109: 784-812

7 Hoskins B J, Karoly D J. The steady linear response of a spherical atmosphere to thermal and orographic forcing. J Atmos Sci, 1981, 38: 1179-1196

8 Webster P J. Mechanisms determining the atmospheric response to sea surface temperature anomalies. J Atmos Sci, 1981, 38: 554-571

9 Webster P J. Seasonality in the local and remote atmospheric response to sea surface temperature anomalies. J Atmos Sci, 1982, 38: 554-571

10 Hoerling M P, Hurrell J W, Xu T, et al. Twentieth century North Atlantic climate change. Part II: Understanding the effect of Indian Ocean warming. Clim Dyn, 2004, 23: 391-405

11 Nitta T. Global features of the Pacific-Japan Oscillation. Meteor Atmos Phys, 1989, 41: 5-12

12 Kripalani R H, Kulkarni A, Singh S V. Association of the Indian summer monsoon with the Northern Hemisphere mid-latitude circulation. Int J Climatol, 1997, 17: 1055-1067

13 Sardeshmukh P, Hoskins B J. The generation of global rotational flow by steady idealized tropical divergence. J Atmos Sci, 1988, 45: $1228-1251$

14 Hoskins B J, Rodwell M J. A model of the Asian summer monsoon. Part I: The global scale. J Atmos Sci, 1995, 38: 1179-1196

15 Rodwell M J, Hoskins B J. A model of the Asian summer monsoon. Part II: Cross-equatorial flow and PV behavior. J Atmos Sci, 1995, 52: 1341-1356

16 Wang B, Wu R, Lau K M. Interannual variability of the Asian summer monsoon: Contrasts between the Indian and the western North Pacific-East Asian monsoons. J Clim, 2001, 14: 4073-4090

17 Ding Q, Wang B. Circumglobal teleconnection in the Northern Hemisphere summer. J Clim, 2005, 18: 3483-3505

18 Ding Q, Wang B. Intraseasonal teleconnection between the summer Eurasian wave train and the Indian monsoon. J Clim, 2007, 20: 3751-3767

19 Lin H. Global extratropical response to diabatic heating variability of the Asian summer monsoon. J Atmos Sci, 2009, 66: 2697-2712

20 Huang R. The East Asia/Pacific teleconnection pattern of summer circulation and climate anomaly in East Asia. Acta Meteorol Sin, 1992, 6: 25-37

21 Chen Y, Chao J. Conservation of wave action and development of spiral Rossby waves (in Chinese). Sci China Ser B-Earth Sci, 1983, 7: 661-672

22 Lee S K, Wang C, Mapes B E. A simple atmospheric model of the local and teleconnection responses to tropical heating anomalies. J Clim, 2008, 22: 227-284

23 Wang B, Xie X. Low-frequency equatorial waves in shear flow. Part I: Stable waves. J Atmos Sci, 1996, 53: 449-467

24 Chao J P. On the dynamics of orographically produced finite perturbations in baroclinic westerlies (in Chinese). Acta Meteorol Sin, 1957, 28: $303-313$

25 Jaw J J. The formation of the semi-permanent center of action in relation to the horizontal solenoidal field. J Meteor, 1946, 3: 103-144

26 Charney J G. The dynamics of long waves in a baroclinic westerly current. J Meteorol, 1947, 4: 135-163

27 Kuo H L. Dynamic instability of two-dimensional nondivergent flow in a barotropic atmosphere. J Meteorol, 1949, 6: 105-122

28 Eady E T. Long waves and cyclone waves. Tellus, 1949, 1: 33-52

29 Pedlosky J. Geophysical Fluid Dynamics. Berlin: Springer-Verlag, 1979. 624

30 Tung K K. Initial-value problems for Rossby waves in a shear flow with critical level. J Fluid Mech, 1983, 133: 443-469

31 Lau K M, Lim H. On the dynamics of equatorial forcing of climate teleconnection. J Atmos Sci, 1984, 41: 161-176

32 McHall Y L. Large-scale perturbations in extratropical atmosphere. Part I: On Rossby waves. Adv Atmos Sci, 1993, 10: 169-180

33 Branstator G. Horizontal energy propagation in a barotropic atmosphere with meridional and zonal structure. J Atmos Sci, 1983, 40: 1689-1708

34 Hoskins B J, Ambrizzi T. Rossby wave propagation on a realistic longitudinally varying flow. J Atmos Sci, 1993, 50: 1661-1671

35 Branstator G. Circumglobal teleconnections, the jet stream waveguide, and the North Atlantic Oscillation. J Clim, 2002, 15: 1893-1910

36 Holton J R. An Introduction to Dynamic Meteorology, 4th ed. Boston: Academic Press, 2004. 535

37 Baines P G, Frederiksen J S. Baroclinic instability on a sphere in two-layer models. Q J Roy Meteorol Soc, 1978, 104: 45-68

38 Frederiksen J S. Instability of planetary waves and zonal flows in two-layer models on a sphere. Q J Roy Meteorol Soc, 1978, 104: 841-872

39 Lighthill M J. Waves in Fluids. Cambridge, England: Cambridge University Press, 1978. 504

40 Bueh C, Shi L, Ji L, et al. Features of the EAP events on the mediumrange evolution process and the mid- and high-latitude Rossby waves activities during the Meiyu period. Chinese Sci Bull, 2008, 53: 610-623

Open Access This article is distributed under the terms of the Creative Commons Attribution License which permits any use, distribution, and reproduction in any medium, provided the original author(s) and source are credited. 